\title{
Preliminary Evaluation of the Field and Laboratory Emission Cell (FLEC) for Sampling Attribution Signatures from Building Materials
}

\author{
Scott D Harvey ${ }^{1 *}$, Lijian $\mathrm{He}^{2}$ and Jon H Wahl ${ }^{1}$
}

${ }^{1}$ Pacific Northwest National Laboratory, Richland, WA 99352, USA

${ }^{2}$ Department of Chemistry, University of South Carolina, Columbia, SC, USA

\begin{abstract}
Clandestine laboratories [e.g., drug, explosive, or chemical warfare (CW)] can be processed for chemical evidence that identifies the synthetic targets and reaction paths. Further, trace impurities contained in the product constitute a fingerprint that can correlate laboratories, associate distributed product (i.e., a terrorist $\mathrm{CW}$ attack) with the production laboratory, or relate various attacks. This phenomenological study evaluates the field and laboratory emission cell (FLEC) for its suitability for sampling volatile attribution signatures. Dissipation of a wide range of attribution signature representatives was studied from a variety of typical building materials using FLEC sampling Results showed rapid and near complete analyte evaporation from metal, intermediate permanence on Teflon, and strong retention on vinyl tiles. FLEC also proved useful for sampling residues left after dissipation of a sulfur mustard stimulant. In summary, preliminary evaluation of FLEC for forensic attribution applications looks promising. Advantages, practical considerations, and disadvantages of FLEC sampling are discussed.
\end{abstract}

Keywords: Forensic science; Attribution signatures; Chemical warfare agents; Clandestine laboratory; Field and laboratory emission cell; Chemical analysis

\section{Introduction}

Processing clandestine laboratories by law enforcement personnel is problematic due to the unknown hazards associated with the materials involved. Therefore, a top priority is often limited to the safe disposal of chemicals without emphasizing the analysis of trace chemical information at these scenes that may have forensic value. Field sampling techniques that do not require dismantlement and transport of building materials to a laboratory environment have potential to aid in these chemical investigations. Sampling techniques designed to characterize chemical residues at a clandestine laboratory can identify synthetic targets and, by identification of reactants and intermediates, delineate what synthetic route was used for production. A variety of clandestine laboratory scenarios exist including those involved in illicit production of drugs, explosives, and chemical warfare (CW) agents. The presence of related residues that originate from unreacted reagents, degradation products, side-reaction products, or impurities in the synthetic starting materials or solvents can yield forensic signatures that can be compared to other laboratories to determine whether the production processes are correlated. Further advantages of characterizing attribution signatures associated with the final product become obvious once the product is distributed. For example, upon intentional release of CW agent in a building during a terrorist attack, characteristic attribution signatures will be present. Fingerprinting these signatures will allow correlation to other related attacks, and to the originating clandestine production laboratory. Ultimately this approach will give clues that can aid tracking and identifying the perpetrator. Although work described here is focused principally on CW attribution signatures, the approach is equally applicable to illicitly produced explosives and drugs.

Detailed laboratory studies of volatile residues are possible using containment chambers; however, this approach cannot be applied to field situations and, further, chamber studies cannot adequately represent the complexities of the indoor air environment [1]. A number of extraction techniques, including solvent, accelerated solvent, and supercritical fluid extractions, can be applied to study agent dissipation from building materials [2]. Extraction approaches have the disadvantages of being destructive (because a portion of the building material must be removed), laboratory-based, and potentially too aggressive (because numerous matrix interferences may also be extracted). A number of field-based, analytical-sampling techniques, including passive flux samplers that adsorb volatile organic compounds onto sorbents or chemically treated strips, have been developed to examine emissions of volatile organics from building materials. For capture of formaldehyde, acetaldehyde, and other carbonyls, flux samplers often contain 2,4-dinitrophenyl hydrazine (DNPH)-coated sorbents or sheets $[3,4]$.

Recently, the field and laboratory emission cell (FLEC) has gained popularity for in-field sampling of surfaces for volatile organic chemical emissions [5]. FLEC sampling has gained popularity because of its ability to collect emissions in complex field environments, which has led to its widespread acceptance, especially in Europe [6]. A diagram of the FLEC sampling device is shown in Figure 1. The FLEC apparatus consists of a stainless steel plate that seals over the flat material surface being studied. Purified gas is introduced around the periphery of the plate, causing laminar flow toward the center. Purge gas containing volatile organics from the surface is directed towards a collection stage that consists of sorbent traps [7] or an impinger [8]. A slight overpressure is typically used to prevent backflow of room air into the apparatus during sampling. Flows are accurately controlled by adjusting the gas flow into the apparatus and the flow rate of the sampling pumps. Various purge gases (usually air or nitrogen) [9] having a range of relative humidity levels have been described $[9,10]$. The FLEC apparatus also can be used in passive mode in combination with solid-phase micro-extraction sampling [11].

*Corresponding author: Harvey SD, Pacific Northwest National Laboratory, Richland, WA 99352, USA, E-mail: scott.harvey@pnl.gov

Received June 21, 2012; Accepted August 24, 2012; Published August 30, 2012

Citation: Harvey SD, He L, Wahl JH (2012) Preliminary Evaluation of the Field and Laboratory Emission Cell (FLEC) for Sampling Attribution Signatures from Building Materials. J Forensic Res 3:164. doi:10.4172/2157-7145.1000164

Copyright: (c) 2012 Harvey SD. This is an open-access article distributed under the terms of the Creative Commons Attribution License, which permits unrestricted use, distribution, and reproduction in any medium, provided the original author and source are credited. 


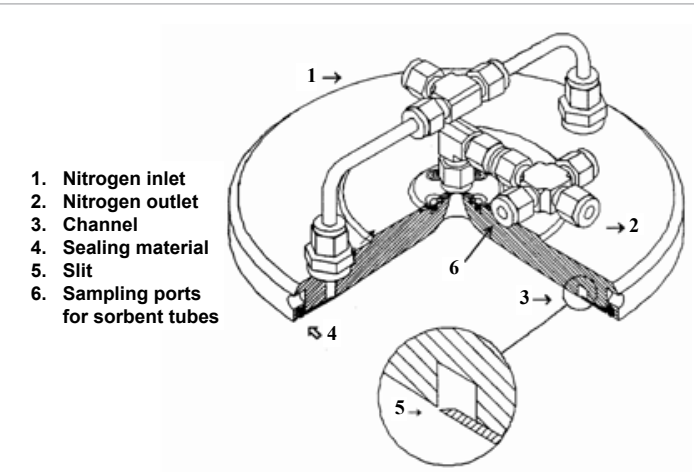

Figure 1: Diagram that shows show a cut-away view of the FLEC sampling apparatus. Drawing modified from the FLEC - Field and Laboratory Emission Cell product brochure and used with permission from Markes International.

The technical literature addressing FLEC focuses almost exclusively on emissions from building materials, with a few citations focused on related topics such as determining diffusion and partition coefficients for water and volatile organic compounds and permeability through materials including polyvinyl chloride composites [12], concrete [13], and membranes [14]. Overall, these studies have demonstrated the significant dynamic complexity defining indoor air quality [1518]. For example, a given material would emit numerous volatile compounds whose concentrations in the air would depend on possible sinks (underlying material the source is applied to as well as other materials in the room). In addition, atmospheric oxidants form secondary volatile products by reacting with the volatile compounds and the surface matrix [19]. Several studies have derived complex mathematical models for emissions from multi-component surfaces, and have experimentally verified the models using FLEC sampling [20,21]. A number of studies have examined the effects of ultraviolet curing in the manufacture of building materials using either the FLEC or related sampling approaches [22,23]. Emissions with varying material temperatures also have been studied $[9,24]$. Several studies examined approaches to reduce emissions by thermal pretreatment [25], by including a variety of natural compounds (i.e., urea, catechin, vanillin) [26] and, in one study, by the application of a nanoparticuate coating of calcium hydroxide to neutralize acidic emissions [27].

Dissipation of analytes from building materials is a process that depends on a complex interplay between the compounds and materials. The chemical and physical properties of the analyte are fundamentally important, as are the properties of the building materials; with the composite sum of interactions between the two largely defining the rate of analyte dissipation. Analyte/material interactions include partitioning mechanisms, pore penetration, analyte diffusion within the material, specific chemical interactions between the analyte and the material, and catalytic effects that may lead to analyte decomposition. Because these interactions are complex, examining dissipation trends based solely on physical and chemical properties of the analyte give only limited insight. Systematic studies addressing dissipation are possible but require extensive experimentation and, considering the time invested, yield limited information. This study, therefore, takes a broader more generalized phenomenological approach to examine the behavior of a wide variety of compound classes on various different representative building surfaces. The selected analytes and materials broadly parallel the behavior of analyte/material interactions expected to be encountered in clandestine laboratories.

The goal of this phenomenological study was to evaluate the suitability of the FLEC sampling approach for forensic collection of volatile attribution chemicals that may remain in clandestine laboratories or after distribution of the synthetic target (i.e., after a terrorist event involving a CW agent). This study examines dissipation from building materials (i.e., Teflon, galvanized sheet steel, and vinyl composition floor tiles) of CW agent simulants, active $\mathrm{CW}$ agent degradation and/or hydrolysis products, formulation stabilization additives, and general representatives of synthetic starting materials, byproducts, and solvent impurities that may persist in illicit formulations produced in clandestine laboratories. We also examined the residues left after the evaporation of a sulfur mustard stimulant, 2-chloroethyl ethylsulfide, (CEES), again looking for possible attribution signatures. The compounds studied consisted of attribution signatures that are likely to have high forensics value and probes that covered a broad range of volatilities, acid-base interactions, and polar-apolar interactions. The overall goal of this application is to offer a simple and documented approach for the collection of residual components within a building to aid with source identification and sample correlation. As discussed above, the existing FLEC literature focuses mostly on continuous emission of volatiles from manufactured building materials. To our knowledge, studies laying the groundwork for forensic attribution applications have not been suggested or described. The overall feasibility of applying FLEC sampling for forensic characterization of residues on building materials is experimentally evaluated and discussed.

\section{Materials and Methods}

\section{Analytical standards}

A 12-component Grob gas-chromatographic capillary column evaluation mixture was obtained from Restek (Bellefonte, PA, USA). Napthalene was purchased from Supelco (Bellefonte, PA, USA) as a $1000 \mu \mathrm{g} / \mathrm{mL}$ methylene chloride solution. Additional analytes including dimethyl methylphosphonate (DMMP), diethyl methylphosphonate (DEMP), triethylamine, and CEES were purchased from SigmaAldrich (St. Louis, MO, USA). 2-(Ethylthio)ethanol was obtained from Alpha Aesar (Ward Hill, MA, USA).

A spike standard was prepared by diluting a mixture of the Grob mix, naphthalene, DMMP, DEMP, and triethylamine with methylene chloride. The spike standard also served as the highest concentration instrument calibration standard. Further instrument calibration standards were prepared by diluting the concentrated standard 2-, 4-, 8-, 20-, 40-, and 200-fold with methylene chloride. The analyte concentrations for the spike standard and the low-level instrument calibration standard are summarized in Table 1.

\section{Building materials}

Virgin grade PFTE that was $1.57 \mathrm{~mm}$ (0.062 in.) thick was obtained from Professional Plastics (Fullerton, CA, USA). Galvanized sheet steel (26 gauge, 0.0217 in. thick), produced by National Manufacturing (Sterling, IL, USA), was obtained via the Internet. Vinyl composition floor tile (Armstrong, Lancaster, PA, USA, \#51899, imperial texture) certified for low organic volatile organic compound emission was purchased from Home Depot. All materials were either supplied as, or cut into, 12 in. by 12 in. squares prior to testing. Some experiments used waxed floor tiles that were treated with four coats of Green Solutions Floor Seal and Finish (Spartan Chemical Co., Maumee, OH, USA). The wax was allowed to thoroughly dry between coats, and the coated tiles were allowed to further dry for several weeks before use. Surfaces of the materials were characterized by scanning electron microscopy (SEM) using a JEOL JSM-7001F Field Emission SEM instrument (Tokyo, Japan) by secondary electron imaging. Samples were attached 
Citation: Harvey SD, He L, Wahl JH (2012) Preliminary Evaluation of the Field and Laboratory Emission Cell (FLEC) for Sampling Attribution Signatures from Building Materials. J Forensic Res 3:164. doi:10.4172/2157-7145.1000164

Page 3 of 8

to carbon tape on aluminum stubs and then carbon-coated to decrease the charging effect under the electron beam. Secondary electron images were taken at $10 \mathrm{KeV}$ at a $3.0 \mathrm{~nm}$ resolution.

\section{FLEC sampling}

The FLEC system, consisting of a FLEC device and two sampling pumps, was purchased from Markes International (Wilmington, DE, USA). The Chematec model FL-1001 pumps provided with the FLEC device powered off a $12 \mathrm{~V}$ DC power source. Tenax TA sorbent tubes (Gerstel Inc., Baltimore, MD, USA) were conditioned overnight at $320^{\circ} \mathrm{C}$ with $35 \mathrm{~mL} / \mathrm{min}$ nitrogen flow using a model TC2 tube conditioner (Gerstel) prior to use. FLEC sampling used dry nitrogen purge gas at a flow of $100 \mathrm{~mL} / \mathrm{min}$ per Tenax trap with a $50 \mathrm{~mL} / \mathrm{min}$ overflow. Two sorbent tubes are used per FLEC device. After sampling, the FLEC was cleaned by removing the O-ring gasket and Teflon ferrules, rinsing the stainless steel unit with ethanol, and drying for several hours in a vacuum oven held at $80^{\circ} \mathrm{C}$. After removal from the oven, the FLEC was allowed to cool to ambient temperature before use.

\section{GC $\times$ GC-MS analysis}

Chemical analyses for the FLEC sorbent collections were performed on a Leco Pegasus 4D GC×GC-MS system (LECO Corp., St. Joseph, MI, USA) equipped with a Gerstel multipurpose sampler (MPS2) and thermal desorption unit (TDU)/cooled injection system (CIS) (Gerstel). Two-dimensional gas chromatography (GC×GC) is a multidimensional separation technique that separates a sample sequentially in two different columns. Two columns with different specificities are chosen to maximize the number of mixture components that can be separated. In general, GC $\times$ GC-MS provides greatly enhanced separations and improved sensitivity, which is comparable to typical single-ion monitoring approaches, but it collects the full mass spectral acquisition range. Ultra-high purity helium, set at $1 \mathrm{~mL} / \mathrm{min}$ constant flow, was used as the carrier gas. The experimental analysis conditions are summarized in Table 2.

\section{Compound recoveries from tenax}

Quantification was based on integrated peak volumes (the twodimensional equivalent of peak areas in conventional chromatograms) from unknown samples compared to a seven-point calibration curve. The calibration curve was constructed by injecting $1.0 \mu \mathrm{L}$ amounts of the calibration standards onto a standard Tenax TA sorbent tube and analyzing by GC $\times$ GC-MS. The upper limits of the calibration curves

\begin{tabular}{|c|c|c|c|c|c|}
\hline $\begin{array}{l}\text { Compound Number/ } \\
\text { Name, } \\
\text { Concentration, or Mass }\end{array}$ & Name & $\begin{array}{l}\text { High-level Calibration } \\
\text { Standard }(\mathrm{ng} / \mu \mathrm{L})\end{array}$ & $\begin{array}{l}\text { Low-level Calibration } \\
\text { Standard }(\mathrm{ng} / \mu \mathrm{L})\end{array}$ & $\begin{array}{l}\text { Method Detection } \\
\quad \text { Limit (ng) }\end{array}$ & Relevancy to this Study \\
\hline 1 & $n$-Decane & 28.0 & 0.140 & 0.08 & Reference compound \\
\hline 2 & $n$-Undecane & 29.0 & 0.145 & 0.12 & Reference compound \\
\hline 3 & DMMP & 34.4 & 0.175 & 0.08 & $\begin{array}{c}\text { Synthetic precursor and simulant for G-series-like } \\
\text { nerve agents }\end{array}$ \\
\hline 4 & 2,3-Butanediol & 53.0 & 0.265 & 0.66 & $\begin{array}{c}\text { Similar to the thiodiglycol, a synthetic precursor and } \\
\text { hydrolysis product of distilled mustard }\end{array}$ \\
\hline 5 & DEMP & 35.0 & 0.175 & 0.27 & $\begin{array}{c}\text { Synthetic precursor and simulant for V-and G-series } \\
\text { nerve agents }\end{array}$ \\
\hline 6 & 1-Octanol & 36.0 & 0.180 & 0.09 & $\begin{array}{l}\text { Alcohols are hydrolysis products of G-series nerve } \\
\text { agents }\end{array}$ \\
\hline 7 & Methyl decanoate & 42.0 & 0.210 & 0.23 & Similar to methylphosphonate nerve agents \\
\hline 8 & $\begin{array}{l}\text { Methyl } \\
\text { undecanoate }\end{array}$ & 42.0 & 0.210 & 0.31 & Similar to methylphosphonate nerve agents \\
\hline 9 & Naphthalene & 35.0 & 0.175 & 0.05 & $\begin{array}{c}\text { Simulates aromatic character of some agents (such as } \\
\text { adamsite or diphenylchloroarsine) }\end{array}$ \\
\hline 10 & $\begin{array}{l}\text { Methyl } \\
\text { dodecanoate }\end{array}$ & 41.0 & 0.205 & 0.42 & Similar to methylphosphonate nerve agents \\
\hline 11 & 2,6-Dimethylaniline & 32.0 & 0.160 & 0.06 & \\
\hline 12 & 2,6-Dimethylphenol & 32.0 & 0.160 & 0.05 & $\begin{array}{l}\text { The incapacitating agent BZ contains a weakly acidic } \\
\text { hydrogen (i.e., the diphenylcarbinol portion of BZ) }\end{array}$ \\
\hline 13 & $\begin{array}{l}\text { 2-Ethylhexanoic } \\
\text { acid }\end{array}$ & 38.0 & 0.190 & 1.13 & $\begin{array}{c}\text { Similar to some agent hydrolysis products (e.g., } \\
\text { benzilic acid from BZ) }\end{array}$ \\
\hline ------ & Nonanal & 40.0 & 0.200 & Not determined & $\begin{array}{l}\text { Represents irritation agents (e.g., formaldehyde, } \\
\text { malonaldehyde, crotonaldehyde, etc.) }\end{array}$ \\
\hline ------ & Triethylamine & 37.2 & 0.186 & Not determined & $\begin{array}{l}\text { Used as a stabilizer (acid scavenger) in some CW } \\
\text { formulations }\end{array}$ \\
\hline ------ & Dicyclohexylamine & 31.0 & 0.155 & Not determined & Similar to stabilizers used in some formulations \\
\hline
\end{tabular}

Table 1: Calibration standard concentration ranges and method detection limits. The high-level calibration standard also was used to spike the material surfaces.

\section{Component}

GC Column 1

GC Column 2

\section{Modulator}

Injection

Gerstel TDU/CIS4

(Gerstel Inc., Baltimore, MD, USA)

\section{Settings}

$30 \mathrm{~m} \times 250 \mu \mathrm{m}, \mathrm{d}_{\mathrm{f}}=0.25 \mu \mathrm{m}$ SolGel-Wax, (SGE, Inc. Austin, TX, USA) Initial: $35^{\circ} \mathrm{C}$ hold for 10 minutes, $5^{\circ} \mathrm{C} / \mathrm{min}$ to $250^{\circ} \mathrm{C}, 250^{\circ} \mathrm{C}$ hold for 5 minutes

$2 \mathrm{~m} \times 100 \mu \mathrm{m}, \mathrm{d}_{\mathrm{f}}=0.4 \mu \mathrm{m}$ 007-1701, (Quadrex Corp. Woodbridge, CT, USA) $+10^{\circ} \mathrm{C}$ offset from column 1

$+25^{\circ} \mathrm{C}$ offset, $5 \mathrm{sec}$ modulation period

TDU Splitless mode, Initial $30^{\circ} \mathrm{C}$ ramped $12^{\circ} \mathrm{C} / \mathrm{sec}$ to $300^{\circ} \mathrm{C}$ hold $5 \mathrm{~min}$ at $50 \mathrm{~mL} / \mathrm{min}$ (total of $5.5 \mathrm{~min}$ ) then: CIS4 Splitless injection for $75 \mathrm{sec}$, initial $-50^{\circ} \mathrm{C}$ ramped $12^{\circ} \mathrm{C} / \mathrm{sec}$ to $300^{\circ} \mathrm{C}$ hold $3 \mathrm{~min}$ (total of $3.58 \mathrm{~min}$ ) then: GC run initiated 
ranged from 28 to $53 \mathrm{ng}$, depending on the specific probe. Periodic continuing calibration verification (CCV) checks were made by comparing the recovery of test probes in a level-six calibration standard (spike standard diluted by a factor of two) to the standard curve. The $\mathrm{CCV}$-check recovery values within the range of 80 to 120 percent were considered to be acceptable, recoveries outside this range prompted generation of a new calibration curve.

Method detection limits (MDLs) were determined by applying $1.0 \mu \mathrm{L}$ of the lowest level calibration standard to Tenax and analyzing by $\mathrm{GC} \times \mathrm{GC}-\mathrm{MS}$. This procedure was repeated seven times, and the standard deviation, based on peak volume, was calculated for each compound. The MDL for each compound was the standard deviation multiplied times the Student's $t$ value (i.e., $\mathrm{t}=3.14$ for a one-sided test with six degrees of freedom at the 99 percent confidence level).

\section{Compound recovery from materials at various post- application times}

To assess recoveries of the compounds from the materials at $\mathrm{t}=0.0 \mathrm{~min}, 1.0 \mu \mathrm{L}$ of the spike standard was applied to the surface of each material, and FLEC sampling was initiated immediately after the solvent evaporated. If a peak area obtained was outside the linear portion of the standard curve range, quantification was considered to be approximate; these values are specifically identified in the figure captions. All material recovery studies were performed in duplicate, using two sorbent tubes per experiment.

Longer post-application periods required application of larger quantities of compounds to allow the evaporative decay to be monitored. In these studies, $50 \mu \mathrm{l}$ of the spike standard was applied, and the surface was sampled after 0.5, 1.0, 3.0, and $5.0 \mathrm{hr}$. Materials were placed on a draft-free laboratory bench that was exposed to the room fluorescent lights during compound evaporation. Duplicate data were collected for each post-application time on each material.

\section{CEES residue study}

This study was performed by depositing $700 \mu \mathrm{L}$ of CEES on galvanized sheet steel coupons and sampling the residue left after either 1.5 or $3.0 \mathrm{hrs}$. Evaporation was performed in a hood in the presence of fluorescent lights. Tentative identifications of unknown compounds were based on matches with a National Institute of Standards and Technology 2005 mass-spectral database. The tentative identifications were verified chromatographically when possible by obtaining retention time and mass spectral matches between an authentic standard and the analysis of an experimental FLEC sorbent trap.

\section{Results and Discussion}

\section{Compound relevancy}

Table 1 (far right column) briefly describes the relevancy of the studied compounds for chemical attribution applications. Table 1 presents only a few of many examples and is not intended to be comprehensive list. Several dialkyl methylphosphonates (DMMP and DEMP) were chosen because these compounds are established surrogates for G-series nerve agents. In addition, these same compounds can also be used as starting materials for the synthesis of nerve agents and, therefore, they may be present in the final CW formulations. Organic carboxylic esters contained in the test mixture are also chemically similar to many of the G-series nerve agents. Likewise, the test mixture 2,3-butanediol component is similar to thiodiglycol, the synthetic precursor and hydrolysis product of distilled mustard. 2,3-Butanediol is also similar to both glycerol, a precursor for the explosive nitroglycerine, and 1,4-butanediol, a recreational drug that is converted in vivo to $\gamma$-hyroxybutyrate, the "date rape drug". Several compounds listed in Table 1 are either weak acids, strong acids, aldehydes, or have aromatic character as represented by 2,6-dimethylphenol, ethylhexanoic acid, nonanal, or naphthalene, respectively. All these chemical functionalities are extensively represented in various attribution signatures associated with clandestine laboratories, as summarized in Table 1. Several amines were included in the study to represent the acid scavengers that are often added to $\mathrm{CW}$ formulations as well as to represent basic drugs and their precursors. Finally, several $n$-alkanes were included as chromatographic retention time reference markers.

\section{Compound recoveries from tenax}

Spikes applied directly to the Tenax sorbent and analyzed by GC $\times$ GC-MS gave calibration curves with linear regression correlation coefficients greater than 0.98 for all test probes, except for the amines (triethylamine and dicyclohexylamine) and nonanal. Amines and the aldehyde could not be quantitatively determined because the calibration data contained unacceptable scatter. The aldehyde came close to meeting our quantitative criterion and could be reliably determined qualitatively in samples. On the other hand, the severe losses observed for the amines would preclude qualitative analysis. The less-than-ideal chromatographic behavior of these compounds could be attributed to a number of possible causes, but most likely, it was the result of adsorptive losses of these reactive compounds on surfaces of the sorbent trap, the heated injection port, or the analytical separation columns. Although these targets were not quantified, they remained in the spike standard. The MDLs for the compounds presented in Table 1 ranged from $1.13 \mathrm{ng}$ for 2-ethylhexanoic acid to $50 \mathrm{pg}$ for naphthalene. The MDL values correspond to the minimum quantity of analyte that can be determined with 99 percent certainty that the true quantity is greater than zero.

\section{Compound recoveries from materials at $\mathrm{t}=\mathbf{0 . 0} \mathrm{hr}$}

Initial time trials $(\mathrm{t}=0.0 \mathrm{hr})$ applied $1.0 \mu \mathrm{L}$ of spike standard to the materials and immediately implemented FLEC sampling as described earlier. The results for Teflon, galvanized sheet steel, and vinyl composition floor tile test surfaces using the FLEC apparatus are summarized in Figure 2. The amount recovered during each trial was the total quantity of compound on the two Tenax traps (corrected for the amount lost through the overflow port) compared to the amount initially applied. The values shown in Figure 2 are the average recoveries for the duplicate trials. Errors reported for each compound are the recovery range between the two trials divided by two.

As seen in Figure 2, galvanized sheet steel and Teflon behave similarly, although recoveries from galvanized sheet steel were generally higher for the lower-volatility compounds than observed from the Teflon, suggesting a hydrophobic partitioning retention mechanism on Teflon. In contrast, the vinyl composition floor tile adsorbs a much higher percentage of the test probes than the other surfaces, possibly because of the greater porosity of this material. Because public building floors are generally sealed with wax products, we also examined vinyl composition floor tiles after they had been treated with a commercial sealant. We thought that the wax treatment may seal the pores and, in general, enhance test compound recoveries. This treatment, however, did not result in significant differences in compound recoveries over untreated vinyl composition floor tiles. The tile results shown in Figure 2 , therefore, are representative of both waxed and non-treated vinyl composition floor tiles. Possible reasons for this behavior are discussed below. 
Citation: Harvey SD, He L, Wahl JH (2012) Preliminary Evaluation of the Field and Laboratory Emission Cell (FLEC) for Sampling Attribution Signatures from Building Materials. J Forensic Res 3:164. doi:10.4172/2157-7145.1000164

\section{Compound recoveries from materials at $\mathrm{t}=0.5-5.0 \mathrm{hr}$}

Typical two-dimensional, total-ion chromatograms obtained after a 1-hr dissipation period are illustrated in Figure 3 for the three surface materials. Each two-dimensional chromatogram depicts the presence of hundreds of compounds, with each appearing as a separate spot in the two-dimensional space. The multidimensional GC $\times$ GC approach helps ensure that all the analytes can be separated from each other and from other matrix interferences that might be collected.

Figures 4-6 show compound recoveries from galvanized sheet steel, Teflon, and vinyl composition floor tiles, respectively, at the 0.5-, 1.0-, 3.0-, and 5.0-hr post-spike time periods. The profiles obtained from galvanized sheet steel (Figure 4) show little was collected other than 2-ethylhexanoic acid $\left(\mathrm{BP}=228^{\circ} \mathrm{C}\right)$, and a lesser amount of methyl dodecanoate $\left(\mathrm{BP}=262^{\circ} \mathrm{C}\right)$. The higher permanence of the lower boiling carboxylic acid suggests specific interactions with the material compared to the ester. This may be due to acid/base interactions with surface zinc hydroxide and/or zinc carbonate formed from the exposure of the zinc galvanization to the atmosphere. The most likely explanation for the low quantity of the other probes is the rapid and near complete evaporation of the more volatile compounds from the metal surface. Although adsorption cannot be entirely discounted, it is an unlikely explanation for these results because the compounds studied have such diverse properties, including their volatilities and polarities.

The profile for Teflon is shown in Figure 5. Some of the more volatile $n$-alkanes have completely dissipated from this substrate after only $0.5 \mathrm{hr}$. The other less-volatile compounds show the expected progressive evaporative decays over the $5.0 \mathrm{hr}$ study. With the exception of naphthalene, the hydrophobic Teflon seems to display stronger retention of the larger molecular weight test probes relative to galvanized sheet steel, again suggesting a partition retention mechanism. Almost all the compounds have dissipated from Teflon after $3.0 \mathrm{hr}$ with the exception of the highest boiling compounds, the methyl esters and the 2-ethylhexanoic acid.

Evaporation from the vinyl composition floor tiles gives an entirely different unique dissipation profile (Figure 6). In contrast with

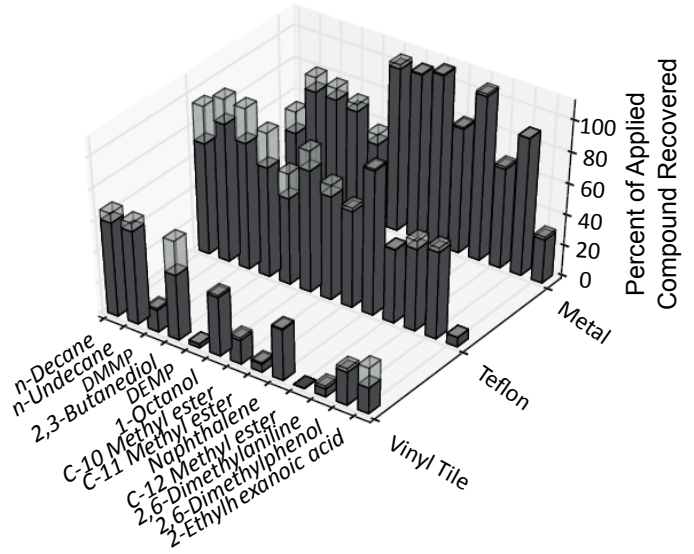

Figure 2: Recovery of compounds using FLEC sampling from galvanized sheet steel, Teflon, and vinyl composite floor tile immediately after application $(t=0)$. Materials show dramatically different adsorption properties. The bottom portion of the bars represent the mean $(n=2)$, whereas the top error portion of the bars represent the recovery range between the two trials divided by two. Graphics script was written in-house using Python software to allow the inclusion of error bars in the three-dimensional plot representations of the FLEC sampling data.

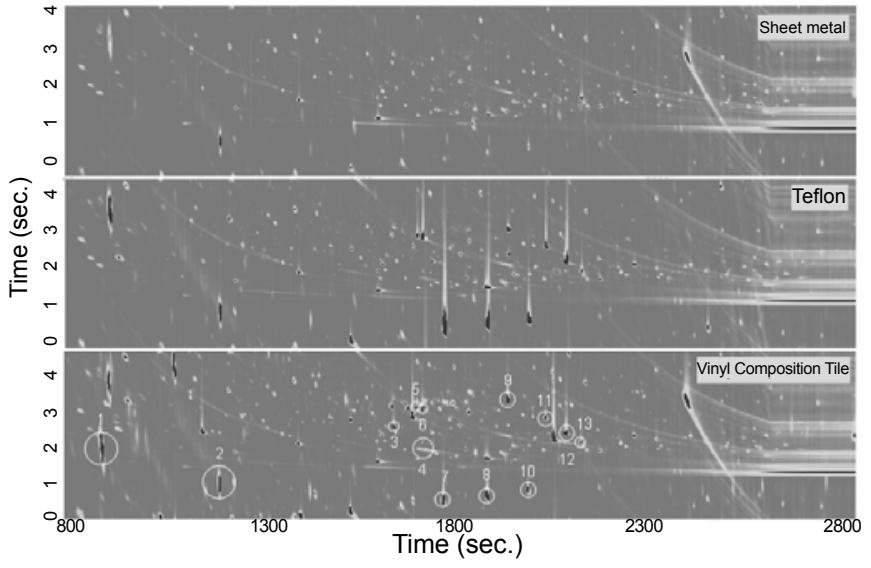

Figure 3: Representative two-dimensional total ion chromatograms obtained from the test probes as collected by FLEC sampling from galvanized sheet steel (top), Teflon (center), and vinyl composition floor tile (bottom) at the 1 $\mathrm{hr}$ post-application period. The light areas in the grayscale chromatographic depiction show the baseline signal, whereas the darker gray areas represent the signal values. The signal intensities for all three chromatogram are normalized to allow direct comparison. The 13 test probe analytes that were quantitatively studied are identified in the bottom chromatogram by the numbers given in Table 1. Analysis conditions are further described in the text and in Table 2.

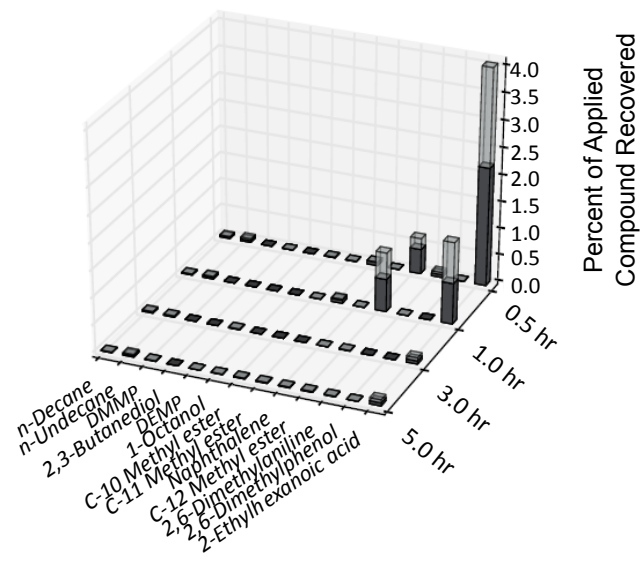

Figure 4: Profiles of compounds dissipating from galvanized sheet steel at various post-application times up to $5.0 \mathrm{hr}$.

galvanized sheet steel and Teflon, immediate depletion of the most volatile compounds was not observed. For example, large quantities of alkanes and DMMP were present after $0.5 \mathrm{hr}$. The vinyl composition floor tiles retain significant amounts of many test probes after $5.0 \mathrm{hr}$, which is unique among the materials studied. We attribute this result to analyte penetration and slow release from the rough and possibly porous structure of the vinyl composition tiles, along with partition into the vinyl composite material matrix. In general, these results are in agreement with Meininghaus et al. [28] who ranked the retentive properties of several building materials and found polyvinyl chloride flooring to be more retentive than wall coverings, but less retentive than carpet, gypsum board, or chipboard.

Compound recovery from waxed vinyl composition floor tiles was also studied over the $5.0 \mathrm{hr}$ period. The dissipation profiles obtained were very similar to the non-waxed floor tiles. Similar behavior between waxed and non-waxed floor tiles was also observed in the $t=0$ series. 
Citation: Harvey SD, He L, Wahl JH (2012) Preliminary Evaluation of the Field and Laboratory Emission Cell (FLEC) for Sampling Attribution Signatures from Building Materials. J Forensic Res 3:164. doi:10.4172/2157-7145.1000164

Page 6 of 8

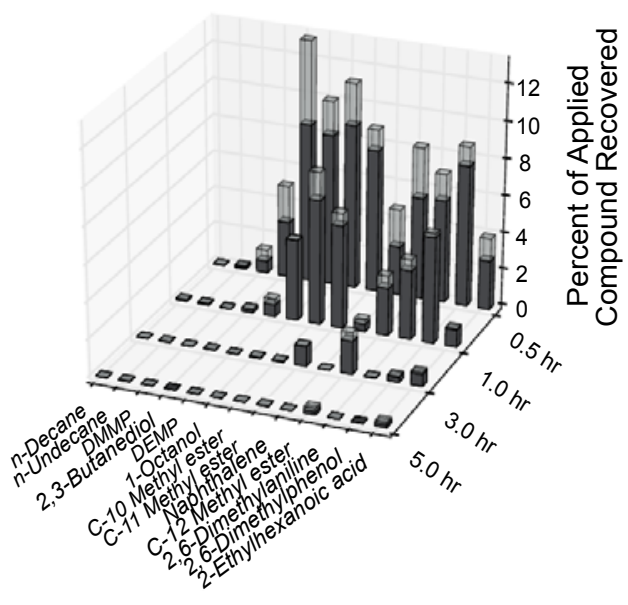

Figure 5: Profiles of compounds dissipating from Teflon at various postapplication times up to $5.0 \mathrm{hr}$. Compounds observed in higher quantities in the $0.5 \mathrm{hr}$ sample, as well as the highest three levels in the $1.0 \mathrm{hr}$ sampling, exceed the maximum linear calibration point; therefore, quantification may not be accurate.

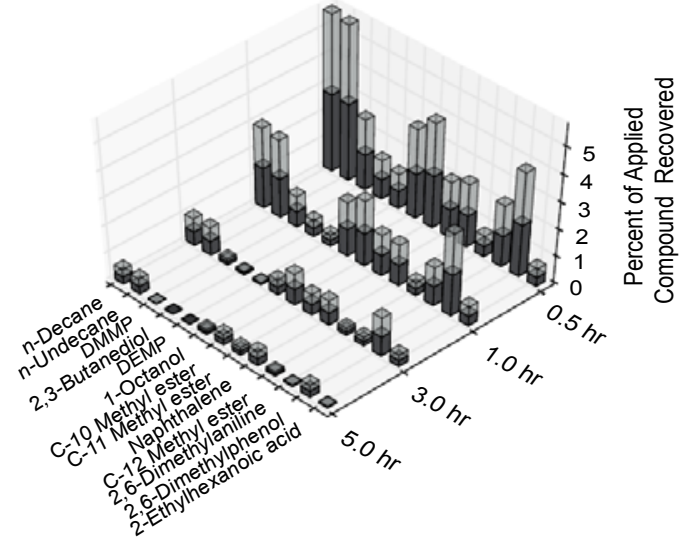

Figure 6: Profiles of compounds dissipating from vinyl composition floor tile at various post-application times up to $5.0 \mathrm{hr}$. Compounds observed in higher quantities in the $0.5 \mathrm{hr}$ sample period exceed the maximum calibration point; therefore, quantification may not be accurate. Because of limited linearity for naphthalene, values above 1.25 percent underestimate the quantity actually present.

Strong compound permanence on the vinyl composition floor tile suggests this material would be desirable for longer period sampling of clandestine laboratories, with the caveat that this material will also remain hazardous longer due to the slow-release kinetics.

Insight into the different behavior for the various materials was gained from examining the SEM images. SEM studies demonstrated the galvanized sheet steel and Teflon were non-porous and fairly smooth. In contrast, the vinyl composition floor tile was relatively rough and appears to have a porous structure. Analyte penetration into the tile pores provide an explanation, in part, why the more volatile compounds dissipate slowly from the surface. Images obtained for the waxed vinyl composition floor tile surface demonstrated that his surface was the smoothest of all the materials studied. As mentioned above, compound adsorption was similar on waxed and non-waxed floor tiles. This behavior could be due to different mechanisms; the waxed floor tile may have superior partitioning capability for the test compounds that compensate for its lack of surface porosity. On the other hand, we noticed that, after the trials, a slightly visible dullness remained on the floor tiles where the spike had been applied to both the waxed and non-waxed vinyl composition tiles. This may indicate the methylene chloride solvent $(50 \mu \mathrm{L})$ temporarily softened the vinyl composition surface allowing compound penetration into the top surface of the matrix. This explanation could also explain the similar test probe dissipation profiles.

\section{CEES residue study}

Residue remaining after evaporation of CEES, a sulfur mustard stimulant, was investigated to further evaluate FLEC sampling of residues. The galvanized sheet steel surface was chosen for this study for several reasons. First, we wanted to facilitate evaporation of the parent compound to accomplish the study within a reasonable time frame. Based on the studies presented in Figures 4 through 6, metal would provide the most rapid dissipation. This is important because about $750 \mathrm{mg}$ of CEES was deposited compared to the time-course studies in which less than $2.65 \mu \mathrm{g}$ of each compound was used. Second, a surface was desired that would result in complex chemical transformations of the parent stimulant. The nonporous metal surface ensures CEES was exposed to the fluorescent lights in the hood to facilitate photodecomposition. Further, the metal surface can catalyze various CEES transformations, resulting in unique and often reactive products. The composition of a residue left after evaporation of CEES could include less volatile impurities contained in the commercial product, reaction products formed on the metal surface, products formed by reaction of intermediates with remaining CEES and residues, and hydrolysis products formed by reaction with atmospheric water. Other investigators have characterized photo-catalytic decomposition products of CEES using gas chromatography/mass spectroscopy (GCxGC-MS) in studies focused on decommissioning CW munitions $[29,30]$.

FLEC sampling found the amount of parent CEES collected at both the 3.0 and $1.5 \mathrm{hr}$ post-application period exceeded the amount of 2-chloroethyl ethyl disulfide (an observed impurity and/ or transformation product) by 73 and 5 times, respectively, based on integration of total ion current chromatograms. Accordingly, the CEES-to-disulfide ratio was approximately 15 times higher at $3.0 \mathrm{hr}$ than at $1.5 \mathrm{hr}$. The decrease in the less-volatile disulfide relative to CEES with time suggests processes are occurring that are more complex than simple evaporation.

The relative amounts of CEES and 2-chloroethyl ethyl disulfide were compared by integration of the extracted ion current chromatograms. The mass spectral ions chosen were $m / z 124$ for CEES and $m / z 156$ for the disulfide compound. This approach was more accurate than calculations based on total ion current integrations because it is less prone to interferences. After $3.0 \mathrm{hr}$, only 22 percent of the CEES (and 3 percent of the disulfide impurity) were collected compared to the 1.5 hr sampling period.

Compounds in the $3 \mathrm{hr}$ sample that were tentatively identified by spectral library matches include 2-chloroethyl ethyl disulfide, 1,4-dithiane, 2-(ethylthio)ethanol, 1-[(2-chloroethyl)thio]-2-(ethylthio)ethane, 3-(propylthio)propionic acid, and bis[2-(ethylthio)ethyl] ether. The presence of 2-(ethylthio)ethanol was verified by a match of retention time and the mass spectrum with an authentic standard. Other tentatively identified compounds were not commercially available to serve as standards. This proof-of-principle experiment demonstrated that FLEC sampling can provide detailed chemical analysis data of residues 
Citation: Harvey SD, He L, Wahl JH (2012) Preliminary Evaluation of the Field and Laboratory Emission Cell (FLEC) for Sampling Attribution Signatures from Building Materials. J Forensic Res 3:164. doi:10.4172/2157-7145.1000164

remaining after dissipation of the majority of the parent compound. Residual compounds may include trace quantities of parent compound as well as attribution markers that may aid in identification of the manufacturing laboratory.

\section{Conclusions}

The purpose of this phenomenological study was to provide a preliminary evaluation of FLEC sampling of residues representing attribution signatures from building materials.

Dissipation of selected analytes from a variety of building materials was conducted to gain insight on the permanence of signatures on various materials. Analytes studied represented synthetic targets, starting material, by-products, and synthetic impurities that could serve as effective attribution signatures. Analyte dissipation was characterized at various post-application times on a number of representative building materials using FLEC sampling. Initial studies demonstrate the Tenax thermal desorption and GCxGC-MS analysis conditions used were capable of quantitatively analyzing a broad range of compounds with the exception aldehydes and amines. Although the scatter in the calibration curves for aldehydes was too high for accurate quantitative analysis, qualitative analysis for this compound class was possible. FLEC sampling combined with GCxGCMS analysis demonstrated that different materials showed different tendencies to adsorb the test probes immediately after application. Overall, galvanized sheet steel showed the least adsorption. Teflon showed rapid depletion of the more volatile compounds, with the less volatile probes showing a stronger association with the hydrophobic Teflon compared to galvanized sheet steel. Vinyl composition floor tile, however, demonstrated strong absorption of the test probes with concomitant slower dissipation, and was the only material to retain significant quantities of the volatile $n$-alkanes. Comparison between waxed vinyl composition floor tiles and non-waxed vinyl composition tiles showed very little differences in compound adsorption.

Time trials examined dissipation from the surfaces from 0.5 to 5.0 hrs. Results indicate very rapid and almost complete evaporation of microgram amounts of the test probes from galvanized sheet steel. In fact, all compounds studied were almost completely undetected after 3.0 hrs. Teflon showed a similar yet unique dissipation profile. In common with the galvanized sheet steel, Teflon showed rapid and complete evaporation of the highly volatile compounds (light hydrocarbons and DMMP). On the other hand, the slower release of the less volatile methyl esters and 2-ethylhexanoic acid from Teflon resulted in these compounds being detected in the $3.0 \mathrm{hr}$ sample. Vinyl composition floor tile gave a very different release profile. The floor tile adsorbed and slowly released most of the compounds studied, including the volatile alkanes. A number of compounds persisted on vinyl composition tile into the $5.0 \mathrm{hr}$ post-application sampling period. Strong permanence of probes on vinyl tiles suggest this material maybe targeted for FLEC sampling in clandestine laboratories to extract the broadest range of attribution signatures, especially if a reasonable period has elapsed since the laboratory has been shut down.

Additional studies focused on a residue left after an application of a bulk quantity ( $750 \mathrm{mg}$ ) of CEES (a sulfur mustard stimulant) to galvanized sheet steel. This study was undertaken because many chemical agents dissipate rapidly and completely before sampling can occur. In the case of CW synthesis in a clandestine laboratory and subsequent product distribution in an attack, identification of the agent used, along with the unique synthetic signatures might rely entirely on the analysis of remaining residues. In the CEES experiment, the parent compound was identified along with a host of chemically related constituents. This study demonstrates FLEC headspace collection techniques are suitable for trace residual components that may have forensic attribution importance.

Sampling with the FLEC apparatus is straightforward, versatile, and readily amendable to a number of forensic sampling situations. FLEC sampling is compatible with field use, can adequately address the complex dynamics of an indoor air environment, is non-destructive, and is easy to use. Moreover, accessories are commercially available to allow sampling from walls, ceilings, carpet, and upholstery. Although laboratory-based FLEC sampling often uses a purge gas humidified to contain specific moisture, the studies we describe use dry purge gas to simplify the instrumental requirements for field use. Sampling equipment needed in addition to the FLEC apparatus include: 1) sorbent traps, 2) compact gas sampling pumps, 3) power supply for pumps, and 4) a source of dry gas. The pumps used for this study could be powered either off a $12 \mathrm{~V}$ battery or $12 \mathrm{~V} \mathrm{DC}$ from a line voltage transformer (120 V AC to $12 \mathrm{~V} \mathrm{DC}, 400 \mathrm{~mA})$. Small $(\sim 1 \mathrm{~L})$ high-pressure tanks that contain $\sim 100 \mathrm{~L}$ of inert gas are suitable for this application and would provide adequate gas for approximately 20 sampling cycles. The FLEC, sorbent traps, pumps, and purge gas source can be preassembled immediately before sampling so rapid placement in the field by personnel wearing full personal protective equipment, or even by remote controlled robots, is possible. The use of FLEC does have a few disadvantages, namely it is expensive, relatively heavy (to create a sampling seal), requires cleaning before redeployment, and does not seem applicable to the analysis of amines using the analysis conditions described herein. Although passive samplers can be easier and more cost effective to simultaneously deploy in number, they will not be capable of sampling the range of analytes at low trace concentrations as the FLEC apparatus.

In summary, our research indicates that the FLEC methodology is capable of collecting a wide range of trace-level attribution signatures that may be encountered in clandestine laboratories while collecting minimal matrix interferences. In addition, our studies show sampling should take into account the radically different dissipation profiles from different building materials. The experimental data demonstrate that immediately after a spill the more volatile attribution signatures were rapidly dissipated from materials like metal and Teflon, whereas the vinyl tiles strongly sorbed the signatures and release them slowly over time. Based on these results vinyl floor tiles would be preferred for FLEC sampling of attribution signatures in clandestine laboratories if considerable time had passed since lab closure. Overall, the FLEC approach shows high potential for aiding forensic investigations of clandestine laboratories as well as for sample correlation of the distributed product.

\section{Acknowledgements}

Funding for this work was provided through contract HSHQPM10X00041 to Pacific Northwest National Laboratory by the U.S. Department of Homeland Security, Science and Technology Directorate. The authors wish to thank Alison D. Eckberg and Brian H. Clowers at Pacific Northwest National Laboratory for providing SEM images of the materials and for writing the Python graphics script, respectively.

\section{References}

1. Schripp T, Fauck C, Salthammer T (2010) Chamber studies on mass-transfer of di(2-ethylhexyl)phthalate (DEHP) and di-n-butylphthalate (DnBP) from emission sources into house dust. Atmos Environ 44: 2840-2845.

2. Wahl JH, Colburn HA (2010) Extraction of chemical impurities for forensic investigations: A case study for indoor releases of a sarin surrogate. Build Environ 45: 1339-1345 
Citation: Harvey SD, He L, Wahl JH (2012) Preliminary Evaluation of the Field and Laboratory Emission Cell (FLEC) for Sampling Attribution Signatures from Building Materials. J Forensic Res 3:164. doi:10.4172/2157-7145.1000164

3. Shinohara N, Kai Y, Mizukoshi A, Fujii M, Kumagai K, et al. (2009) On-site passive flux sampler measurement of emission rates of carbonyls and VOCs from multiple indoor sources. Build Environ 44: 859-863.

4. Shinohara N, Fujii M, Yamasaki A, Yanagisawa Y (2007) Passive flux sampler for measurement of formaldehyde emission rates. Atmos Environ 41: 40184028.

5. Wolkoff P, Nielsen PA (1996) A new approach for indoor climate labeling of building materials - emission testing, modeling, and comfort evaluation. Atmos Environ 30: 2679-2689.

6. Zhang LZ, Niu JL (2003) Laminar fluid flow and mass transfer in a standard field and laboratory emission cell. Int J Heat Mass Transf 46: 91-100.

7. Wolkoff P, Clausen PA, Nielsen PA (1995) Application of the field and laboratory emission cell "FLEC" - performance study, intercomparison study, and case study of damaged linoleum in an office. Indoor Air 5: 196-203.

8. Ham JE, Wells JR (2009) Surface chemistry of dihydromyrcenol (2,6-dimethyl7-octen-2-ol) with ozone on silanized glass, glass, and vinyl flooring tiles. Atmos Environ 43: 4023-4032.

9. Wolkoff P (1998) Impact of air velocity, temperature, humidity, and air on longterm voc emissions from building products. Atmos Environ 32: 2659-2668.

10. Clausen PA, Xu Y, Kofoed-Sørensen V, Little JC, Wolkoff P (2007) The influence of humidity on the emission of di-(2-ethylhexyl) phthalate (DEHP) from vinyl flooring in the emission cell "FLEC". Atmos Environ 41: 3217-3224.

11. Nicolle J, Desauziers V, Mocho P, Ramalho O (2009) Optimization of FLECSPME for field passive sampling of VOCs emitted from solid building materials. Talanta 80: 730-737.

12. Järnström H, Saarela K, Kalliokoski P, Pasanen AL (2008) Comparison of VOC and ammonia emissions from individual PVC materials, adhesives and from complete structures. Environ Int 34: 420-427.

13. Luo R, Niu JL (2006) Determining diffusion and partition coefficients of VOCs in cement using one FLEC. Build Environ 41: 1148-1160.

14. Zhang LZ (2006) Evaluation of moisture diffusivity in hydrophilic polymer membranes: A new approach. J Membrane Sci 269: 75-83.

15. Li F, Niu J, Zhang L (2006) A physically-based model for prediction of VOCs emissions from paint applied to an absorptive substrate. Build Environ 41: 1317-1325.

16. Zhang LZ, Niu JL (2003) Effects of substrate parameters on the emissions of volatile organic compounds from wet coating materials. Build Environ 38: 939-946.

17. Wolkoff P (1999) How to measure and evaluate volatile organic compound emissions from building products. A perspective. Sci Total Environ 227: 197213.
18. Haghighat $F$, De Bellis $L$ (1998) Material emission rates: literature review, and the impact of indoor air temperature and relative humidity. Build Environ 33 : 216-277.

19. Nicolas M, Ramalho O, Maupetit F (2007) Reactions between ozone and building products: impact on primary and secondary emissions. Atmos Environ 41: 3129-3138.

20. Zhang LZ, Niu JL (2004) Modeling VOCs emissions in a room with a singlezone multi-component multi-layer technique. Build Environ 39: 523-531.

21. Hu HP, Zhang YP, Wang XK, Little JC (2007) An analytical mass transfer model for predicting $\mathrm{VOC}$ emissions from multi-layered building materials with convective surfaces on both sides. Int J Heat Mass Transf 50: 2069-2077.

22. Kim S (2010) Control of formaldehyde and TVOC emission from wood-based flooring composites at various manufacturing processes by surface finishing. $J$ Hazard Mater 176: 14-19.

23. Salthammer T, Bednarek M, Fuhrmann F, Funaki R, Tanabe S-I (2002) Formation of organic indoor air pollutants by UV-curing chemistry. $\mathrm{J}$ of Photochem Photobio A: Chem 152: 1-9.

24. An J-Y, Kim S, Kim H-J, Seo, J (2010) Emission behavior of formaldehyde and TVOC from engineered flooring in under heating and air circulation systems. Build Environ 45: 1826-1833.

25. Kim S, Choi Y-K, Park K-W, Kim JT (2010) Test methods and reduction of organic pollutant compound emissions from wood-based building and furniture materials. Bioresour Technol 101: 6562-6568.

26. Uchiyama S, Matsushima E, Kitao N, Tokunaga H, Ando M, et al. (2007) Effect of natural compounds on reducing formaldehyde emission from plywood. Atmos Environ 41: 8825-8830.

27. Giorgi R, Chelazzi D, Fratini E, Langer S, Niklasson A, et al. (2009) Nanoparticles of calcium hydroxide for wood deacidification: decreasing the emissions of organic acid vapors in church organ environments. J Cult Herit 10: $206-213$

28. Meininghaus R, Salthammer T, Knöppel H (1999) Interaction of volatile organic compounds with indoor materials - a small-scale screening method. Atmos Environ 33: 2395-2401.

29. Martyanov IN, Klabunde KJ (2003) Photocatalytic oxidation of gaseous 2-chloroethyl ethyl sulfide over $\mathrm{TiO}_{2}$. Environ Sci Technol 37: 3448-3453.

30. Vorontsov AV, Lion C, Savinov EN, Smirniotis PG (2003) Pathways of photocatalytic gas phase destruction of HD simulant 2-chloroethyl ethyl sulfide. J Catal 220: 414-423. 